\title{
Simulation models for strategic and tactical management of crops and pastures
}

\author{
J.F. Angus, M. Stapper and J.R. Donnelly
}

CSIRO Division of Plant Industry, GPO Box 1600, Canberra, 2601, Australia

\begin{abstract}
Australian crops and pastures are grown in climates which are relatively variable at present and may become more variable if the global climate changes. Optimal management in relation to this variability has two strands. The best-bet management strategy must be identified for the long-term climate and modified with any climate change. Variation in weather between years, however, is already greater than changes in the mean expected from climate change, so improved management tactics to cope with current variability will lead to systems with longterm resilience.

Examples using the SIMTAG and maNage models are described for improved strategic and tactical management of rainfed wheat. SIMTAG is used to clarify the extent to which regional yields are currently limited by weather and to make a strategic assessment of optimal sowing date. The maNage model is used for tactical management of supplementary $\mathrm{N}$ fertiliser for dryland wheat. maNage shows that the reliability of yield response is increased if the $\mathrm{N}$ is applied at the terminal spikelet stage but only if the amount of stored soil water is above a defined threshold.

Future integration of crop models with pasture models is discussed. Pastures make up the largest landuse on farms in the region. They have special importance because they influence the growth of crops grown in sequence. Modelling the interaction of pastures-crop sequences and crop-crop sequences in relation to weather is important for increasing yields of both crops and pastures.
\end{abstract}

\section{Introduction}

Most crops and pastures in Australia are grown without irrigation and in environments with generally low rainfall and high evaporation. The variability of production is high, as shown for wheat yield for the Wagga Wagga district of south-eastern Australia over the past 40 years (Fig. 1). Yields in this area have a co-efficient of variation of $31 \%$ and a mean annual increase of $26 \mathrm{~kg} \mathrm{ha}^{-1}$ [Connor and Rimmington (1991) show that variability on a regional or national scale is less because of the greater diversity of weather systems]. The need to develop management systems to cope with variability makes agroclimatology an important topic for Australian agriculture.

\section{Strategic management}

Most management decisions in a rainfed environment must be based on the best-bet option which results in the greatest long-term net returns. Results from conventional experimental research are often inadequate for deciding the best bets because of the limited range of seasonal conditions over which experiments are conducted.

The SIMTAG model of wheat (Stapper 1984) has been widely tested on experimental yields of mid-latitude spring wheat. It has strengths in the definition of development stages and in optimising cultivar selection by matching the duration of a crop's development pattern with the duration of growing season. Fig. 1 shows wheat yield simulations of SIMTAG, based on 
daily weather data for 35 years at Wagga Wagga using parameters for specifying local soilwater properties and cultivar-specific development.

The simulated yields greatly exceed reported yields in all except the driest years. The mean reported yield, at 1992 technology level is $50 \%$ of the simulated potential. Clearly the farm yields are not water-limited in most years and the biggest gains are to be made in the most favourable seasons. Furthermore if farms yields rise towards the potential the variability will rise greatly; the co-efficient of variation for simulated yield is $47 \%$.

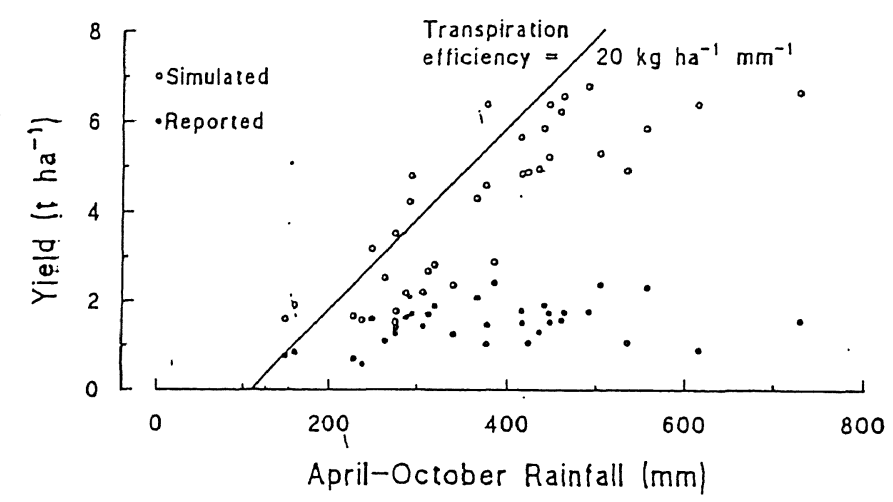

Fig. 1. Reported (0) and simulated (0) wheat yields for the Wagga Wagga district of south eastern Australia in relation to seasonal rainfall. The line represents a transpiration efficiency of $20 \mathrm{~kg} \mathrm{ha}^{-1}$ of grain per mm of rainfall.

Fig. 1 also contains a line representing water-limited yield defined by a soil evaporation loss of $110 \mathrm{~mm}$ and a "transpiration efficiency" of $20 \mathrm{~kg} \mathrm{ha}^{-1}$ of grain per mm of water (French and Schultz 1984). This line defines the upper limit of yield, up to values of about $6 \mathrm{t} \mathrm{ha}^{-1}$ at which factors other than water are limiting. The extent to which the transpiration line and the simulations differ is mostly because of wastage of water through runoff and drainage.

One use of this model is to demonstrate to farmers that factors other than weather limit yields in most seasons. Presumably improvements in crop management could overcome any setbacks due to climatic change. Another use is in simulating strategies for yield increase. Fig. 2 shows the probability of yields not exceeding specified levels for two sowing-date strategies. The yield curve for early sowing indicates higher yields than for late sowing in all years. This model can be used for other strategic decisions such as selecting cultivars with different maturities.

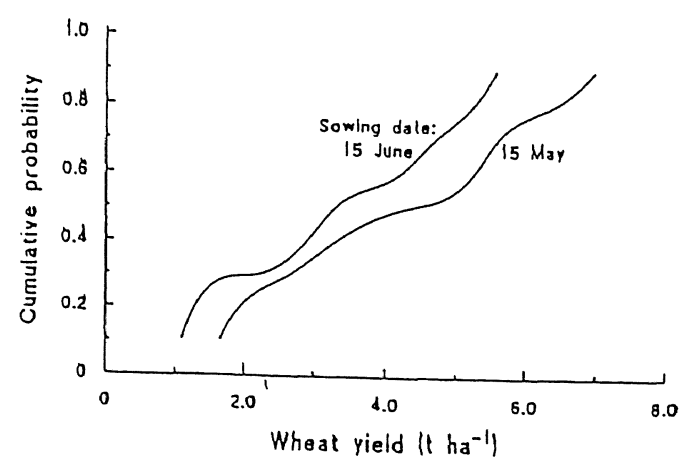

Fig. 2. Cumulative frequency distributions of simulated wheat yields in relation to sowing date for Wagga Wagga, 1944-1983.

\section{Tactical management of $\mathbb{N}$ for dryland crops}

If weather does not normally limit yield, what does? One possibility is the supply of nitrogen. Extensive experimental programs have in the past concentrated on $\mathrm{N}$ applied at sowing and 
have failed to show reliably profitable yield responses (Angus and Fischer 1991). A possible approach is to apply $\mathrm{N}$ after sowing, but only in seasons when there is sufficient soil water. The maNage model uses a simple approach based on the assimilation-respiration-water stress equation of Byrne (1973) and the plant-N functions of Angus and Moncur (1985).

This model was calibrated on experimental data for different levels of $\mathrm{N}$ over several years and was found to fit sets of independent experimental and regional data (Angus, unpublished). The model was run with 99 years of daily weather data for Harden in south-eastern Australia. The simulated mean response to $50 \mathrm{~kg} \mathrm{~N}^{-1}$ applied at sowing was $0.6 \mathrm{t} \mathrm{ha}^{-1}$. The model was run with the tactic of applying $N$ at the terminal spikelet stage only if the soil water content was at least $90 \%$ of the maximum available. With this simulated policy, $N$ was applied in 76 of the 99 years with a mean yield response was 0.7 t ha-1. Fig. 3 shows the predicted probabilities of responses.

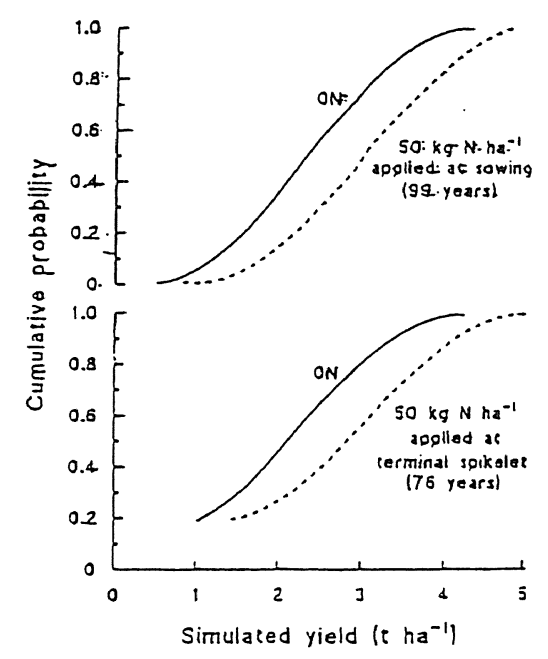

Fig. 3. Cumulative frequency distributions for simulated wheat yields for Harden in south eastern Australia (a) comparing crops receiving no $\mathrm{N}$ and $50 \mathrm{~kg} \mathrm{~N} \mathrm{ha}^{-1}$ at sowing. (b) comparing

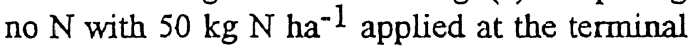
spikelet stage, but only if the soil water was at least $90 \%$ of capacity.

\section{Future directions}

Farmland in south eastern Australia is used more for production of wool and meat from pasture than for crops. Pastures grown in sequence with crops occupy much of the $\sim 60 \mathrm{~m}$ ha of the farmland in the sub-humid zone (i.e. land receiving $\sim 150-450 \mathrm{~mm}$ of growing season rainfall). Crop and pastures interact through the carry-over of soil water, nitrogen, soil-borne disease organisms and weeds from one year to the next.

Models and decision support systems have been developed for management of pastures and animal production (Christian et al. 1978; Moore et al. 1991). These models, driven by daily weather variables, have water-balance and plant growth routines similar to crop growth models, but they are extended to account for the effect of grazing on pasture growth. They are used to predict the most profitable systems of pasture and stock management, for example, the combination of stocking rate of sheep or cattle, age structures of animals, times of lambing or calving and fodder-conservation strategies.

Table 1 Mechanisms through which pastures and crops affect the growth of subsequent crops

\section{Mechanism}

Soil-water depletion

$\mathrm{N}$ fixation

$\mathrm{N}$-mineralisation

Carryover of soil-borne disease

Residues containing foliar disease organisms and possible allelopathic compounds

\section{Model}

Water balance

Legume growth/soil mineral $\mathrm{N}$

Soil water and temperature

Host species, soil water and temperature Residue breakdown 
Our intention is to combine the crop and pasture models in crop-crop and pasture-crop systems so as to account for the effect of pastures on subsequent crops and vice versa. Some mechanisms by which interactions occur between pastures and crops are shown in Table 1 . All are affected by environment. For example, $\mathrm{N}$-fixation is proportional to legume growth, provided that there is no available soil-N (Peoples and Herridge 1989); The breakdown of crop residues is accelerated by summer rainfall. The major disease of wheat, take-all caused by Gaeumannomyces graminis tritici, is strongly affected by spring rainfall (Roget and Rovira 1991). Control of soil-borne diseases with non-host species can lead to high yields of subsequent crops and greater depletion of water and mineral $\mathrm{N}$ from the soil profile (Angus et al. 1991).

For all farm enterprises in south-eastern Australia, models can assist strategic decisions by defining the best bet options in terms of long-term weather. In the drier parts of the region, low potential productivity will limit the inputs and management decisions to an annual choice of crop or pasture species and land preparation at the start of the growing season. For these situations the main tactical options will relate to the timing of the start of the growing season, for which models are also useful. For relatively high-rainfall regions like the ones to which the figures refer, tactics to take advantage of the better seasons can lead to increased yield.

\section{References}

Angus, J.F. and Moncur, M.W. (1985) Models of growth and development of wheat in relation to plant nitrogen. Aust. J. Agric. Res. 36, 537-44.

Angus, J.F., and Fišcher, R.A. (1991). Grain and protein responses to nitrogen applied to wheat growing on a red earth. Aust. J. Agric. Res. 42, 735-46

Angus, J.F., Herwaarden, A.F. van and Howe, G.N. (1991). Productivity and break crop effects of winter-growing oilseeds. Aust. J. Exper. Agric. 31, 669-77

Byrne, G.F. (1973). An approach to growth curve analysis. Agric. Meteorol. 11, 161-168

Christian, K.R., Freer, M., Donnelly, J.L., Davidson, J.L. and Armstrong, J.S. (1978). Simulation of grazing systems. PUDOC, Wageningen.

Connor, D.J. and Rimmington, G.M. (1991). Simulation model and analysis of variability of Australian wheat production. p26-44 In: Shu Geng and C.W. Cady (eds). Climatic variations and change: implications for agriculture in the Pacific Rim. University of California, Davis.

French and Schultz (1984). Water use efficiency of wheat in a Mediterranean-type environment. I. The relation between yield, water use and climate. Aust. J. Agric. Res. 35, 743-764.

Moore, A.D., Donnelly, J.R. and Freer, M. 1991. GrazPlan: An Australian DSS for enterprises based on grazed pastures. Proceedings, International Conference on Decision Support Systems of Resource Management, p 19-22, Texas A\&M University.

Peoples,Mark and Herridge, David (1989). How much nitrogen is fixed by legumes. Agricultural Science (NS) 3, 34-29.

Roget, D.K. and Rovira,A.D. (1991). The relationship between incidence and infection by the take-all fungus, rainfall and yield of wheat in South Australia. Aust. J. Exper. Agric. 31, 50913.

Stapper, M. (1984). SIMTAG: A simulation model of wheat genotypes. Model documentation. University of New England, Armidale. 